\title{
Interaction of $\gamma$-conglutin from Lupinus albus with model phospholipid membranes: Investigations on structure, thermal stability and oligomerization status
}

\author{
Andrea Scirè $^{\mathrm{a}, *}$, Maurizio Baldassarre ${ }^{\mathrm{b}}$, Fabio Tanfani ${ }^{\mathrm{a}}$, Jessica Capraro ${ }^{\mathrm{c}}$, Marcello Duranti $^{\mathrm{c}}$, \\ Alessio Scarafoni ${ }^{\mathrm{C}}$ \\ ${ }^{a}$ Dipartimento di Scienze della Vita e dell'Ambiente, Università Politecnica delle Marche, Ancona, Italy \\ b Department of Biochemistry and Biophysics, Stockholm University, Stockholm, Sweden \\ ${ }^{\mathrm{c}}$ Department of Food, Environmental and Nutritional Sciences, Università degli Studi di Milano, Milan, Italy
}

A R T I C L E I N F O

\section{Keywords:}

$\gamma$-Conglutin

Glycaemia

FT-IR spectroscopy

Oligomerization

Model phospholipid membranes

SUV

DMPG

DOPA

Turbidity

\begin{abstract}
A B S T R A C T
Interaction with model phospholipid membranes of lupin seed $\gamma$-conglutin, a glycaemia-lowering protein from Lupinus albus seeds, has been studied by means of Fourier-Transform infrared spectroscopy at $\mathrm{p}^{2} \mathrm{H} 7.0$ and at $\mathrm{p}^{2} \mathrm{H}$ 4.5. The protein maintains the same secondary structure both at $\mathrm{p}^{2} \mathrm{H} 7.0$ and $\mathrm{p}^{2} \mathrm{H} 4.5$, but at $\mathrm{p}^{2} \mathrm{H} 7.0$ a higher ${ }^{1} \mathrm{H} /{ }^{2} \mathrm{H}$ exchange was observed, indicating a greater solvent accessibility. The difference in $T_{\mathrm{m}}$ and $T_{\mathrm{D} 1 / 2}$ of the protein at the abovementioned $\mathrm{p}^{2} \mathrm{H}$ 's has been calculated around $20^{\circ} \mathrm{C}$. Infrared measurements have been then performed in the presence of DMPG and DOPA at $\mathrm{p}^{2} \mathrm{H}$ 4.5. DMPG showed a little destabilizing effect while DOPA exerted a great stabilizing effect, increasing the $T_{\mathrm{m}}$ of $\gamma$-conglutin at $\mathrm{p}^{2} \mathrm{H} 4.5$ of more than $20^{\circ} \mathrm{C}$. Since $\gamma$-conglutin at $\mathrm{p}^{2} \mathrm{H} 4.5$ is in the monomeric form, the interaction with DOPA likely promotes the oligomerization even at $\mathrm{p}^{2} \mathrm{H}$ 4.5. Interaction between DMPG or DOPA and $\gamma$-conglutin has been confirmed by turbidity experiments with DMPC:DMPG or DOPC:DOPA SUVs. Turbidity data also showed high-affinity binding of $\gamma$-conglutin to anionic SUVs made up with DOPA. The molecular features outlined in this study are relevant to address the applicative exploitation and to delineate a deeper comprehension of the natural functional role of $\gamma$-conglutin.
\end{abstract}

\section{Introduction}

$\gamma$-conglutin from the leguminous plant Lupinus albus accounts for about $4 \%$ of the total seed proteins. It is a multimeric glycoprotein, in which each monomer of 45,446 Da is made up of two polypeptides of about 29 and $17 \mathrm{kDa}$, linked by a disulphide bond. The larger polypeptide is glycosylated. $\gamma$-conglutin has been considered for a long time a seed storage protein, but more recent studies definitely ruled out this function evidencing a multifaceted involvement in plant defence mechanisms triggered by pathogens attacks [1]. As a matter of facts, $\gamma$ conglutin shares structural similarities with a family of glucanase inhibitors widely distributed across the plant kingdom [2,3], such as the xyloglucan-specific endo- $\beta-1,4$-glucanase inhibitors (XEGIPs). Beside its physiological role, $\gamma$-conglutin set off a remarkable pharmacological interest, too. $\gamma$-conglutin was proved to significantly decrease glycaemia in humans and animals when orally administered $[4,5]$. The glucose-lowering effect of the protein was comparable to that obtained with metformin, a well-known hypoglycaemic drug [4]. The applicative fall backs of these findings are relevant, being $\gamma$-conglutin a natural dietary component that could complement pharmacotherapy in the management of diabetes [6]. In vitro approaches indicated that $\gamma$-conglutin can be internalized by human model cells. The intact protein can transit from the apical to the basolateral side of Caco- 2 cell monolayers. Unmodified protein was also detected inside intestinal everted sacs [7]. These findings imply that the protein may be translocated across the intestinal barrier. Moreover, in $\gamma$-conglutin -treated HepG2 the protein was found accumulated inside the cytosol [8]. The mechanisms of the observed cellular uptake and those at the basis of the in vivo effects of the protein are far from being clarified and worth further efforts to be unveiled. The present work fits in this context. Here we present the results about the dynamic structural variations of the protein in solution in the presence of vesicles made of various phospholipids, including

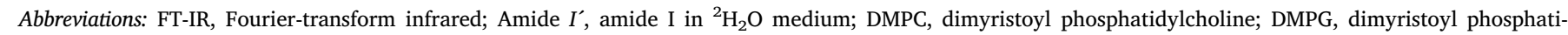
dylglycerol; DOPA, dioleoyl phosphatidic acid; DOPC, dioleoyl phosphatidylcholine; SUV, small unilamellar vesicle

* Corresponding author at: Dipartimento di Scienze della Vita e dell'Ambiente, Universita' Politecnica delle Marche, Via Brecce Bianche, Ancona 60131, Italy.

E-mail address: a.a.scire@univpm.it (A. Scirè). 
DMPG and DOPA, studied by means of Fourier-Transform infrared (FTIR) spectroscopy and turbidity measurements.

\section{Materials and methods}

\subsection{Materials}

Piperazine, deuterium oxide $\left(99.9 \%{ }^{2} \mathrm{H}_{2} \mathrm{O}\right),{ }^{2} \mathrm{HCl}, \mathrm{NaO}^{2} \mathrm{H}$, Hepes, DMPC, DMPG, DOPA and DOPC were purchased from Sigma-Aldrich. All other chemicals used were commercial samples of the purest quality.

\subsection{Protein purification}

The protein was essentially purified according to Capraro et al. (2010). Lupin flour (60 mesh) was defatted with pentane using a Soxlet apparatus and resuspended in distilled water $(1: 20, w / v)$. After stirring for $4 \mathrm{~h}$ at $4{ }^{\circ} \mathrm{C}$, the slurry was centrifuged at $10,000 \times g$ for $30 \mathrm{~min}$ at $4{ }^{\circ} \mathrm{C}$. The globulin fraction contained in the pellet was extracted $(1: 20$, $w / v$ ) with $50 \mathrm{~m} \mathrm{M}$ sodium phosphate buffer, $\mathrm{pH} 7.5$, containing $500 \mathrm{mM}$ $\mathrm{NaCl}$. After stirring for $4 \mathrm{~h}$ at $4^{\circ} \mathrm{C}$, the suspension was centrifuged at $10,000 \times g$ for $30 \mathrm{~min}$ at $4^{\circ} \mathrm{C}$. Aliquots of the supernatant were loaded on a Sephadex G-50 column (GE Healthcare, Milan, Italy) equilibrated with $50 \mathrm{mM}$ sodium phosphate buffer, $\mathrm{pH} 7.5$, for desalting and changing buffer The protein-containing fraction was immediately loaded on DEAE 52-cellulose (Whatman, Maidstone, UK) column equilibrated with in the same buffer. $\gamma$-conglutin was found in the not retained fraction. This solution was adjusted to $\mathrm{pH} 4.5$ with acetic acid, loaded on a Whatman CM-cellulose column equilibrated with $50 \mathrm{mM}$ sodium acetate buffer, $\mathrm{pH} 4.5$, and eluted with the same buffer containing $350 \mathrm{mM} \mathrm{NaCl}$. As last step of purification, an affinity chromatography step with insulin-agarose (Sigma-Aldrich, Milan, Italy) was used. $\gamma$ conglutin solution was loaded on the column equilibrated in $25 \mathrm{mM}$ Tris-HCl, pH 7.2, and eluted with the same buffer containing $200 \mathrm{mM}$ $\mathrm{NaCl}$. The purified protein was finally dialyzed at $4{ }^{\circ} \mathrm{C}$ against milli-Q water, freeze dried and dissolved in the appropriate buffers before use.

\subsection{Preparation of samples for infrared spectroscopy measurements}

$\gamma$-conglutin solutions were analyzed in heavy water medium at $\mathrm{p}^{2} \mathrm{H}$ 7.0 and at $\mathrm{p}^{2} \mathrm{H}$ 4.5. Also, $\gamma$-conglutin was analyzed at $\mathrm{p}^{2} \mathrm{H} 4.5$ in the presence of DMPG or DOPA. Protein samples were prepared by dissolving about $1.5 \mathrm{mg}$ of lyophilized $\gamma$-conglutin in $200 \mu \mathrm{L}$ of $50 \mathrm{mM}$ Hepes/ $\mathrm{NaO}^{2} \mathrm{H} \mathrm{p}^{2} \mathrm{H} 7.0$ (buffer A) or $50 \mathrm{mM}$ piperazine $/{ }^{2} \mathrm{HCl} \mathrm{p}^{2} \mathrm{H} 4.5$ (buffer B) or $50 \mathrm{mM}$ piperazine $/{ }^{2} \mathrm{HCl}, 0.1 \mathrm{M} \mathrm{NaCl}, \mathrm{p}^{2} \mathrm{H} 4.5$ (buffer $\mathrm{C}$ ) for measurements in the presence of DMPG or DOPA. Each $\gamma$-conglutin solution was centrifuged in a $30 \mathrm{~K}$ Amicon ultra 0.5 micro concentrator (Millipore Ireland Ltd., Cork, IRL) at $3000 \mathrm{x} \mathrm{g}, 4^{\circ} \mathrm{C}$, until the volume solution reached approximately $30 \mu \mathrm{L}$. Then, further $200 \mu \mathrm{L}$ of buffer (A or $\mathrm{B}$ ) were added and the solution was re-concentrated. This procedure was repeated five times in order to completely hydrate $\gamma$-conglutin with the chosen buffer. For the experiments in the presence of phospholipids (PLs), $1 \mathrm{mg}$ of DMPG or DOPA, dissolved in chloroform/methanol solution was dried in a small test tube under a stream of nitrogen and then hydrated with the concentrated $\gamma$-conglutin solution obtained as described above. Gentle vortexing led to the formation of a suspension of $\gamma$-conglutin/liposomes. The $\mathrm{p}^{2} \mathrm{H}$ was measured with a standard $\mathrm{pH}$ electrode, and the value was corrected according to $\mathrm{p}^{2} \mathrm{H}=\mathrm{pH}+0.4$ [9].

\subsection{Infrared spectra}

The concentrated $\gamma$-conglutin samples were injected into a thermostatted Graseby Specac 20,500 cell (Graseby-Specac Ltd., Orpington, Kent, UK) fitted with $\mathrm{CaF}_{2}$ windows and a $25 \mu \mathrm{m}$ Mylar spacer. FT-IR spectra were recorded by means of a Perkin-Elmer 1760-X Fourier transform infrared spectrometer using a deuterated triglycine sulphate detector and a normal Beer-Norton apodization function. At least $24 \mathrm{~h}$ before, and during data acquisition, the spectrometer was continuously purged with dry air at a dew point of $-70^{\circ} \mathrm{C}$, produced by a FT-IR purge gas apparatus (Parker Hannifin UK Ltd., Maidstone, Kent, UK). To obtain spectra at different temperatures an external bath circulator (HAAKE F3) was used. Spectra were collected every $2{ }^{\circ} \mathrm{C}$, in the $20-91.5^{\circ} \mathrm{C}$ temperature range. The actual temperature in the cell was controlled by a thermocouple placed directly onto the windows. Spectra of buffers and samples were acquired at $2 \mathrm{~cm}^{-1}$ resolution under the same scanning and temperature conditions. At every fixed temperature, the IR spectrum of the sample or buffer was averaged over 32 repeated accumulations. Correct subtraction of ${ }^{2} \mathrm{H}_{2} \mathrm{O}$ was adjusted to the removal of the ${ }^{2} \mathrm{H}_{2} \mathrm{O}$ bending absorption near $1220 \mathrm{~cm}^{-1}$ [10]. Spectra were processed using the SPECTRUM software from Perkin-Elmer. Secondderivative spectra were calculated over a 9 data-point range $\left(9 \mathrm{~cm}^{-1}\right)$. The self-deconvolution parameters were set with a gamma value of 2.5 and a smoothing length of 60 . Estimation of the secondary structure composition was carried out by curve fitting of the deconvoluted amide $\mathrm{I}^{\prime}$ band using the peak-fitting module included in the OriginPro 7.5 software (OriginLab Corp., Northampton, MA) [9-12]. To calculate the midpoint transitions, namely the temperatures of melting $\left(T_{\mathrm{m}}\right)$ and the temperatures of half deuteration $\left(T_{\mathrm{D} 1 / 2}\right)$, different parameters extrapolated from the FT-IR spectra of the samples were plotted against the temperature, and the raw data were fitted with a sigmoid function as described in [13-15]. Additional thermal behavior analysis was performed as described in [16,17] using Eq. (1) for fitting procedure in OriginPro 7.5 software (OriginLab Corp., Northampton, MA).

\subsection{Preparation of small unilamellar vesicles (SUVs)}

SUVs were prepared by extrusion technique [18] through polycarbonate filters (pore diameter $100 \mathrm{~nm}$ ) using an extruder device from Avanti Polar Lipids Inc. (Alabaster, Ala). Prior to extrusion, lipids of the desired composition were mixed in chloroform/ methanol $(3: 1, v / \mathrm{v})$ into glass test tubes and the solvent was removed in a nitrogen gas stream. The lipid film was hydrated with a solution of $50 \mathrm{mM}$ Hepes/ $\mathrm{NaOH}, 0.1 \mathrm{M} \mathrm{NaCl}, \mathrm{pH} 7.0$ producing multilamellar vesicles (MVs) that were then extruded through polycarbonate filters. The extrusion steps were done at $25^{\circ} \mathrm{C}$ for DOPC and DOPC:DOPA (50:50) mixture and at $40^{\circ} \mathrm{C}$ for DMPC and DMPC:DMPG (50:50) mixture. The final PLs concentration of these stock suspensions was $2.5 \mathrm{mM}$.

\subsection{Turbidity assay}

Turbidity of SUVs samples as a function of increasing concentration of $\gamma$-conglutin was measured in a four-sided quartz cuvette at an excitation and emission wavelength of $550 \mathrm{~nm}$ [19] in a LS50B (Perkin-Elmer) luminescence spectrometer equipped with a thermostated cell for liquid samples. Measurements were done at $25^{\circ} \mathrm{C}$ for DOPC and DOPC:DOPA (50:50) mixture and at $35^{\circ} \mathrm{C}$ for DMPC and DMPC:DMPG (50:50) mixture. The concentration of PLs was $150 \mu \mathrm{M}$ while the concentration of $\gamma$-conglutin was in the range of $0-16 \mu \mathrm{M}$ for DMPC and DMPC:DMPG mixture or $0-3 \mu \mathrm{M}$ for DOPC and DOPC:DOPA mixture. Data were fitted to a one-site binding hyperbolic curve by OriginPro 7.5 software (OriginLab Corp., Northampton, MA).

\section{Results and discussion}

The first part of the work was instrumental to test the adequacy and the robustness of the experimental approach based on FT-IR spectroscopy to investigate the structural features of $\gamma$-conglutin and to set the reference parameters for studying the interactions between the protein and model phospholipid membranes. With this aim we first performed the analysis of $\gamma$-conglutin secondary structure both at $\mathrm{p}^{2} \mathrm{H} 7.0$ and at $\mathrm{p}^{2} \mathrm{H} 4.5$, monitoring its thermal stability. L. albus $\gamma$-conglutin can be 


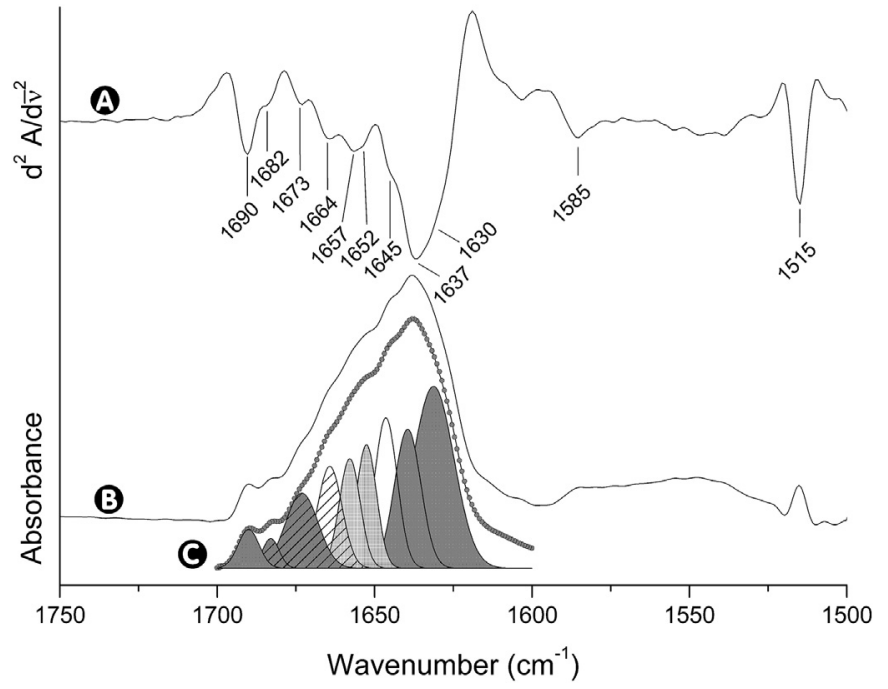

Fig. 1. Second derivative (A), self-deconvoluted (B) and curve-fitting (C) spectra of $\gamma$-conglutin. Spectra were recorded at $20^{\circ} \mathrm{C}$ in ${ }^{2} \mathrm{H}_{2} \mathrm{O}$ medium at $\mathrm{p}^{2} \mathrm{H}$ 7.0. Component bands assigned to $\beta$-strands, $\alpha$-helices and random coils are shaded dark grey, light grey and white, respectively. Bands due to $\beta$-strands and/or turns are shaded dark grey and striped. Bands due to turns are shaded in white and striped. The dotted line represents the sum of the individual component bands.

found either as a tetramer or as a monomer [20]. The quaternary assembling undergoes a tetramer-dimer-monomer transition from neutral to acidic $\mathrm{pH}$. The tetrameric form is prevalent at $\mathrm{pH}$ values above 7.0 and the monomeric status is present exclusively at pHs below 4.5 [20]. Intriguingly, the version of $\gamma$-conglutin purified from L. angustifolius shows a hexameric assembly at pH 7.5 [21], whereas soybean Bg7S homologue has a tetrameric quaternary structure [22] and all other XEGIP-like members are monomeric proteins [22].

Fig. 1 shows the second derivative spectrum (A), the self-deconvoluted spectrum (B) and the curve fitting procedure (C) of $\gamma$-conglutin at $\mathrm{p}^{2} \mathrm{H} 7.0,20^{\circ} \mathrm{C}$. The spectra $1 \mathrm{~A}$ and $1 \mathrm{~B}$ are resolution enhanced spectra obtained from the absorbance spectrum of $\gamma$-conglutin (not shown), necessary to better locate and assign the bands associated to secondary structure elements. Information on the secondary structure of $\gamma$-conglutin can be obtained by analysis of the amide $\mathrm{I}^{\prime}$ band (1700-1600 $\mathrm{cm}^{-1}$ ) [12,23], mainly arising from the backbone $\mathrm{C}=\mathrm{O}$ stretching vibration. In the amide $\mathrm{I}^{\prime}$ region, the resolution-enhanced spectra of $\gamma$-conglutin show nine bands (Fig. 1A and C). The 1630, 1637 and $1690 \mathrm{~cm}^{-1}$ bands are characteristic of $\beta$-sheet structures while the bands at 1682 and $1673 \mathrm{~cm}^{-1}$ may be due to turns and/or $\beta$-sheets [23,24]. The bands at 1652 and at $1657 \mathrm{~cm}^{-1}$ could represent two different population of helices differing in exposure to the solvent $\left({ }^{2} \mathrm{H}_{2} \mathrm{O}\right)$ or in the regularity of folding (distortion) [25]. The band at $1664 \mathrm{~cm}^{-1}$ is assigned to turns while the band at $1645 \mathrm{~cm}^{-1}$ is assigned to unordered structures. The bands below $1620 \mathrm{~cm}^{-1}$ are due to amino acid side chain absorptions. In particular, the 1515 and the $1585 \mathrm{~cm}^{-1}$ bands are due to tyrosines and to ionized carboxyl groups of aspartate residues, respectively [26]. To estimate the secondary structure content of $\gamma$-conglutin at $\mathrm{p}^{2} \mathrm{H} 7.0$, a curve-fitting procedure on the self-deconvoluted spectrum was performed. The result of the curve fitting is shown in Fig. 1C, and reported quantitatively in Table 1. The sum of the individual component bands generated by the curve fitting procedure is shown as a dotted line. The secondary structure composition was found to be $43-54 \% \beta$-sheet, 19\% $\alpha$-helix, 13\% unordered structures and $10-21 \% \beta$-turns. The uncertainty in the assignment of the bands arising from turns structures and the high-frequency components of anti-parallel $\beta$-sheets make their absolute quantification in curve-fitting procedures challenging. Nevertheless, the determined values are in good accordance with previous data obtained with L. angustifolius $\gamma$-conglutin
Table 1

Secondary structure content of $\gamma$-conglutin at $\mathrm{p}^{2} \mathrm{H} 7.0$, as calculated by curve fitting of the self-deconvoluted Amide $I^{\prime}$ band at $20^{\circ} \mathrm{C}$.

\begin{tabular}{lll}
\hline Band assignment & Center $\left(\mathrm{cm}^{-1}\right)$ & Area (\%) \\
\hline$\beta$-sheet & 1630 & 29.0 \\
$\beta$-sheet & 1637 & 14.4 \\
unordered & 1645 & 13.3 \\
$\alpha$-helix & 1652 & 9.8 \\
$\alpha$-helix & 1657 & 8.9 \\
turns & 1664 & 9.8 \\
$\beta$-sheet/turns & 1673 & 9.6 \\
$\beta$-sheet/turns & 1682 & 1.9 \\
$\beta$-sheet & 1690 & 3.2 \\
\hline
\end{tabular}

The $\chi^{2}$ value of the fitting was $1.02 \times 10^{-6}$. The center and the area values are rounded off to the nearest integer and nearest tenths place value, respectively.

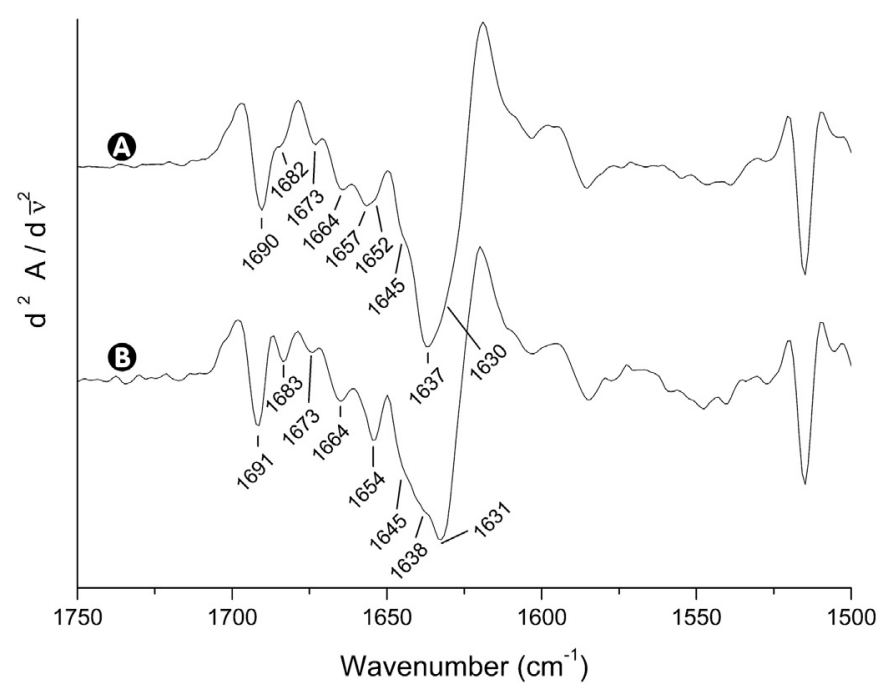

Fig. 2. Second derivative spectra of $\gamma$-conglutin at $p^{2} \mathrm{H} 7.0$ (A) and at $\mathrm{p}^{2} \mathrm{H} 4.5$ (B), at $20^{\circ} \mathrm{C}$.

crystal analysis [21]. These findings indicate that the general folding status of $\gamma$-conglutin is conserved both in solution and in crystalline status.

The resolution-enhanced second derivative spectra of $\gamma$-conglutin at $\mathrm{p}^{2} \mathrm{H} 7.0$ (A) and at $\mathrm{p}^{2} \mathrm{H} 4.5$ (B) are showed in Fig. 2. The protein maintains the same secondary structure elements both at $\mathrm{p}^{2} \mathrm{H} 7.0$ and at $\mathrm{p}^{2} \mathrm{H}$ 4.5. The bands pattern at $\mathrm{p}^{2} \mathrm{H} 4.5$ is similar but not identical to the one at $\mathrm{p}^{2} \mathrm{H} 7.0$, showing a little difference in the position of the bands assigned to beta-sheets. At acidic $\mathrm{p}^{2} \mathrm{H}$ the low and high frequency betasheets bands are now shifted to 1631 and $1638 \mathrm{~cm}^{-1}$ and at $1691 \mathrm{~cm}^{-1}$, respectively. The bands at 1652 and at $1657 \mathrm{~cm}^{-1}$, assigned to alpha-helices at $\mathrm{p}^{2} \mathrm{H} 7.0$, are now replaced by a single band at $1654 \mathrm{~cm}^{-1}$. Since deuteration of proteins causes a downshift in the wavenumber of the $\alpha$-helix and $\beta$-sheet bands [13], these differences could be ascribed to a less compact structure of $\gamma$-conglutin at $\mathrm{p}^{2} \mathrm{H}$ 7.0. This is better evident examining the residual amide II band $\left(1550 \mathrm{~cm}^{-1}\right)$ of $\gamma$-conglutin at $\mathrm{p}^{2} \mathrm{H} 7.0$ and 4.5 (Fig. 3). In ${ }^{2} \mathrm{H}_{2} \mathrm{O}$, due to the ${ }^{1} \mathrm{H} /{ }^{2} \mathrm{H}$ exchange of amide protons with deuterons, the amide II band decreases in intensity with respect to the spectrum obtained in $\mathrm{H}_{2} \mathrm{O}$ medium. This decrease is a measure of the ${ }^{1} \mathrm{H} /{ }^{2} \mathrm{H}$ exchange, which in turn, gives information on the accessibility of the solvent $\left({ }^{2} \mathrm{H}_{2} \mathrm{O}\right)$ to the protein and therefore on protein compactness/flexibility. The greater the intensity decrease, the greater is the ${ }^{1} \mathrm{H} /{ }^{2} \mathrm{H}$ exchange and therefore the accessibility of the solvent into the protein $[10,13]$ and hence the greater the flexibility. Fig. 3 shows that at $20^{\circ} \mathrm{C}$, the intensity of the residual amide II band of $\gamma$-conglutin at $\mathrm{p}^{2} \mathrm{H} 7.0$ is lower (Fig. 3A), compared with the one at $20{ }^{\circ} \mathrm{C}$ and $\mathrm{p}^{2} \mathrm{H} 4.5$ (Fig. 3B), indicating a 


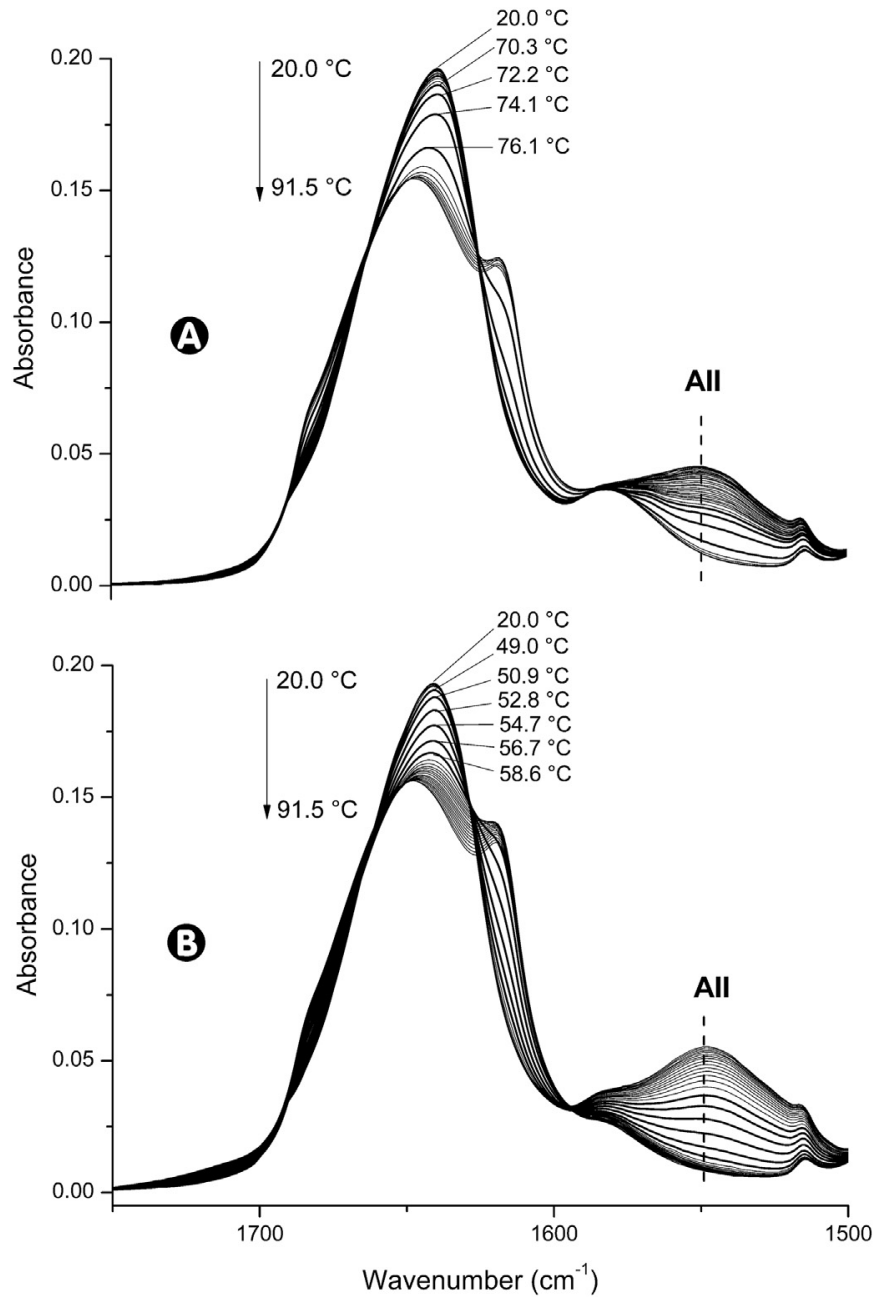

Fig. 3. Temperature-dependent changes in absorbance spectra of $\gamma$-conglutin at $\mathrm{p}^{2} \mathrm{H} 7.0$ (A) and at $\mathrm{p}^{2} \mathrm{H} 4.5$ (B). Spectra were collected in the temperature range from 20 to $91.5^{\circ} \mathrm{C}$ and recorded every $2{ }^{\circ} \mathrm{C}$. The symbol AII stands for residual amide II band absorption at $1550 \mathrm{~cm}^{-1}$.

higher ${ }^{1} \mathrm{H} /{ }^{2} \mathrm{H}$ exchange of $\gamma$-conglutin at $\mathrm{p}^{2} \mathrm{H} 7.0$ as a consequence of a less structural compactness. The greater ${ }^{1} \mathrm{H} /{ }^{2} \mathrm{H}$ exchange of $\gamma$-conglutin at $\mathrm{p}^{2} \mathrm{H} 7.0$ is probably due to the existence of a multimer at this $\mathrm{p}^{2} \mathrm{H}$, where the complete dissociation of histidine side groups allows some salt bridges to be formed [20], while at $\mathrm{p}^{2} \mathrm{H} 4.5$ a global positive charge of the protein prevents any oligomerisation maintaining the protein in a monomeric conformation [20].

When a protein is heated above its characteristic $T_{\mathrm{m}}$ it undergoes significant unfolding and possibly aggregation. The temperature-dependent conformational changes of $\gamma$-conglutin can be analyzed by monitoring different parameters of its FT-IR spectrum as a function of temperature. For instance, a plot of the width of the amide $\mathrm{I}^{\prime}$ band $(\mathrm{W}$ $1 / 2 \mathrm{H}$ ) and of the intensity of the residual amide II band (AII intensity) as a function of temperature may give information on protein denaturation (loss of secondary structure) and on ${ }^{1} \mathrm{H} /{ }^{2} \mathrm{H}$ exchange, respectively (Fig. 4A and B). The former behavior occurs when a protein is heated above its characteristic $T_{\mathrm{m}}$. In this case, it undergoes significant unfolding and aggregation that can be detected as an increase in the width of the amide $\mathrm{I}^{\prime}$ band $[12,14]$. The latter phenomenon occurs when a protein is dissolved in ${ }^{2} \mathrm{H}_{2} \mathrm{O}$ medium. ${ }^{1} \mathrm{H} /{ }^{2} \mathrm{H}$ exchange increases with the increase in temperature and the rate of ${ }^{1} \mathrm{H} /{ }^{2} \mathrm{H}$ exchange increases rapidly when temperature induced relaxation of tertiary structure and/or protein denaturation occur [10]. Fig. 4 shows the thermal denaturation curves of $\gamma$-conglutin at $\mathrm{p}^{2} \mathrm{H} 7.0$ (Fig. 4A) and at $\mathrm{p}^{2} \mathrm{H} 4.5$
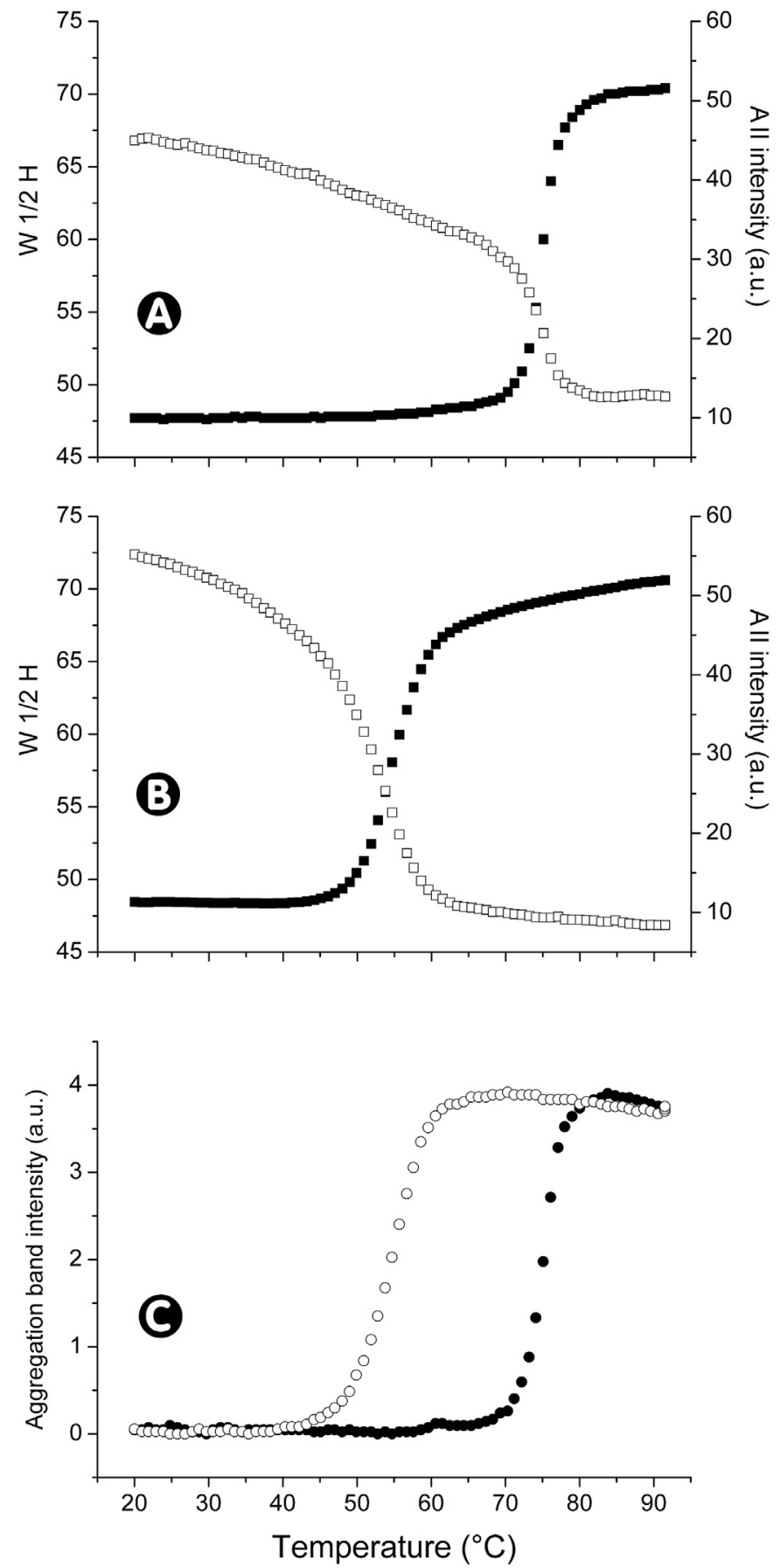

Fig. 4. Temperature-dependent changes in IR spectral parameters for $\gamma$-conglutin at $\mathrm{p}^{2} \mathrm{H} 7.0$ and at $\mathrm{p}^{2} \mathrm{H}$ 4.5. Curves of panel $\mathrm{A}\left(\mathrm{p}^{2} \mathrm{H} 7.0\right)$ and $\mathrm{B}\left(\mathrm{p}^{2} \mathrm{H} 4.5\right)$ represent plots of the width of the amide $\mathrm{I}^{\prime}$ band calculated at one-half of the amide $\mathrm{I}^{\prime}$ band height (W $1 / 2 \mathrm{H}$, symbol $\square$, left scale) and of the intensity of the residual amide II band (AII intensity, symbol $\square$, right scale) as a function of temperature. Melting temperatures $\left(T_{\mathrm{m}}\right)$ and half deuteration temperatures $\left(\mathrm{T}_{\mathrm{D} 1 / 2}\right)$ are reported in Table 2. Curves of panel $\mathrm{C}$ represent the intensity of the band related to protein aggregation $\left(1615 \mathrm{~cm}^{-1}\right)$ as a function of temperature at $\mathrm{p}^{2} \mathrm{H} 7.0$ (symbol $\bigcirc$ ) and at $\mathrm{p}^{2} \mathrm{H} 4.5$ (symbol $\mathrm{O}$ ). Onset of aggregation corresponds to $71^{\circ} \mathrm{C}\left(\mathrm{p}^{2} \mathrm{H} 7.0\right)$ and $49^{\circ} \mathrm{C}\left(\mathrm{p}^{2} \mathrm{H} 4.5\right)$.

\section{(Fig. 4B).}

The temperatures of melting $\left(T_{\mathrm{m}}\right)$ and the temperatures of half deuteration $\left(T_{\mathrm{D} 1 / 2}\right)$ were initially calculated from the curves as described in [13-15] but, to better extract quantitative information from $\mathrm{W} 1 / 2 \mathrm{H}$ and from AII intensity as a function of temperature, we 
Table 2

Parameters of the fitting procedure according to (1) of $\mathrm{W} 1 / 2 \mathrm{H}$ and AII intensity as a function of temperature for $\gamma$-conglutin at $\mathrm{p}^{2} \mathrm{H} 7.0, \mathrm{p}^{2} \mathrm{H} 4.5$ and at $\mathrm{p}^{2} \mathrm{H} 4.5$ in the presence of DMPG or DOPA.

\begin{tabular}{lllll}
\hline & & Amplitude (A) & Steepness (B) & $\begin{array}{l}\text { Inflection } \\
\text { temperature } \\
\left(\mathrm{T}_{0}\right)\end{array}$ \\
& & & & 74.9 \\
$\mathrm{p}^{2} \mathrm{H} 7.0$ & W 1/2H & 22 & -0.65 & 74.1 \\
& AII intensity & 23 & 0.36 & 54.6 \\
$\mathrm{p}^{2} \mathrm{H} 4.5$ & W 1/2H & 21 & -0.35 & 52.5 \\
& AII intensity & 43 & 0.22 & 50.8 \\
$\mathrm{p}^{2} \mathrm{H} 4.5+$ DMPG & W 1/2H & 21 & -0.15 & 48.4 \\
& AII intensity & 28 & 0.20 & 76.9 \\
$\mathrm{p}^{2} \mathrm{H} 4.5+$ DOPA & W 1/2H & 23 & -0.56 & 76.2 \\
& AII intensity & 26 & 0.12 & \\
\hline
\end{tabular}

performed a fit by using the following expression [16,17]:

$\mathrm{Y}(\mathrm{T})=\mathrm{A}\left(1-\left(\frac{1}{1+e^{-B(T-\mathrm{T} 0)}}\right)\right)+(C-D T)$

Here, $\mathrm{Y}$ is the $\mathrm{W} 1 / 2 \mathrm{H}$ or the AII intensity where A represents the amplitude factor connected with the global thermal behavior, its inverse is called "thermal restrain" and represents a global aspect of the system. $\mathrm{B}$ is connected with the transition steepness, moving from smaller to higher value when the transition gets more and more rapid. $T_{0}$ is the inflection temperature that corresponds to the temperature of melting $\left(T_{\mathrm{m}}\right)$ or to the temperature of half deuteration $\left(T_{\mathrm{D} 1 / 2}\right)$ when Eq. (1) is applied for $\mathrm{W} 1 / 2 \mathrm{H}$ or AII intensity, respectively. Lastly, C - DT represents the low temperature vibrational contribution $[16,17]$.

The results of the fitting procedure for $\mathrm{W} 1 / 2 \mathrm{H}$ or AII intensity of $\gamma$ conglutin at $\mathrm{p}^{2} \mathrm{H} 7.0$ and at $\mathrm{p}^{2} \mathrm{H} 4.5$ by applying (1) are reported in Table 2 . The analysis indicates a higher thermal restrain together with a higher inflection temperature for $\gamma$-conglutin at $\mathrm{p}^{2} \mathrm{H} 7.0$ with respect to $\mathrm{p}^{2} \mathrm{H}$ 4.5. It's worth noting that the thermal stability of $\gamma$-conglutin is remarkably greater at $p^{2} \mathrm{H} 7.0$ compared to $\mathrm{p}^{2} \mathrm{H} 4.5$, the difference in $T_{\mathrm{m}}$ and $T_{\mathrm{D} 1 / 2}$ is around $20^{\circ} \mathrm{C}$. A great difference in thermal stability of $\gamma$-conglutin at neutral than at acidic $\mathrm{pH}$ has been observed previously [27], and has been ascribed to the different form of $\gamma$-conglutin at neutral and acidic pH's (multimeric and monomeric, respectively).

Protein aggregation (brought on by protein denaturation) can be monitored plotting a band characteristic of intermolecular interactions [10]. Fig. 4C shows the temperature-dependent intensity of the aggregation band $\left(1615 \mathrm{~cm}^{-1}\right)$ in the second derivative spectra of $\gamma$ conglutin at $\mathrm{p}^{2} \mathrm{H} 7.0$ and at $\mathrm{p}^{2} \mathrm{H}$ 4.5. Both at neutral and acidic pH's $\gamma$ conglutin has the propensity to aggregate, but the onset of aggregation is found at $71{ }^{\circ} \mathrm{C}$ and at $49^{\circ} \mathrm{C}$ for the tetrameric and monomeric form, respectively.

Having carried out the necessary characterization of the structural dynamics of $\gamma$-conglutin, the successive work was directed to study the interaction features and the effects on the thermal stability of the protein of DMPG, DOPA and other PLs. It should be noted that seed proteins have usually acidic pIs but $\gamma$-conglutin is a peculiar protein, since its pI is 8.24 [20]. To assess whether the basic pI of $\gamma$-conglutin could promote ionic interactions between the net negative charge of polar head groups of acidic PLs and the net positive charge of the protein, infrared measurements of $\gamma$-conglutin were also performed in the presence of DMPG and DOPA at $\mathrm{p}^{2} \mathrm{H} 4.5$ (see Material and Methods). Little is known about the PL composition of lupin seeds but Hamama and Bhardwaj reported that phosphatidic acid (PA) and phosphatidylglycerol (PG), even if not belonging to the most abundant classes of PLs detected in seed oil from white lupin, are present at reasonable amounts, ranging from $3.4 \%$ to $2.7 \%$ of total phospholipids for PA and PG, respectively [28].

Fig. 5 shows the thermal denaturation (panel A), ${ }^{1} \mathrm{H} /{ }^{2} \mathrm{H}$ exchange (panel B) and aggregation (panel C) curves of $\gamma$-conglutin at $\mathrm{p}^{2} \mathrm{H} 4.5$ in the absence and in the presence of DMPG or DOPA.
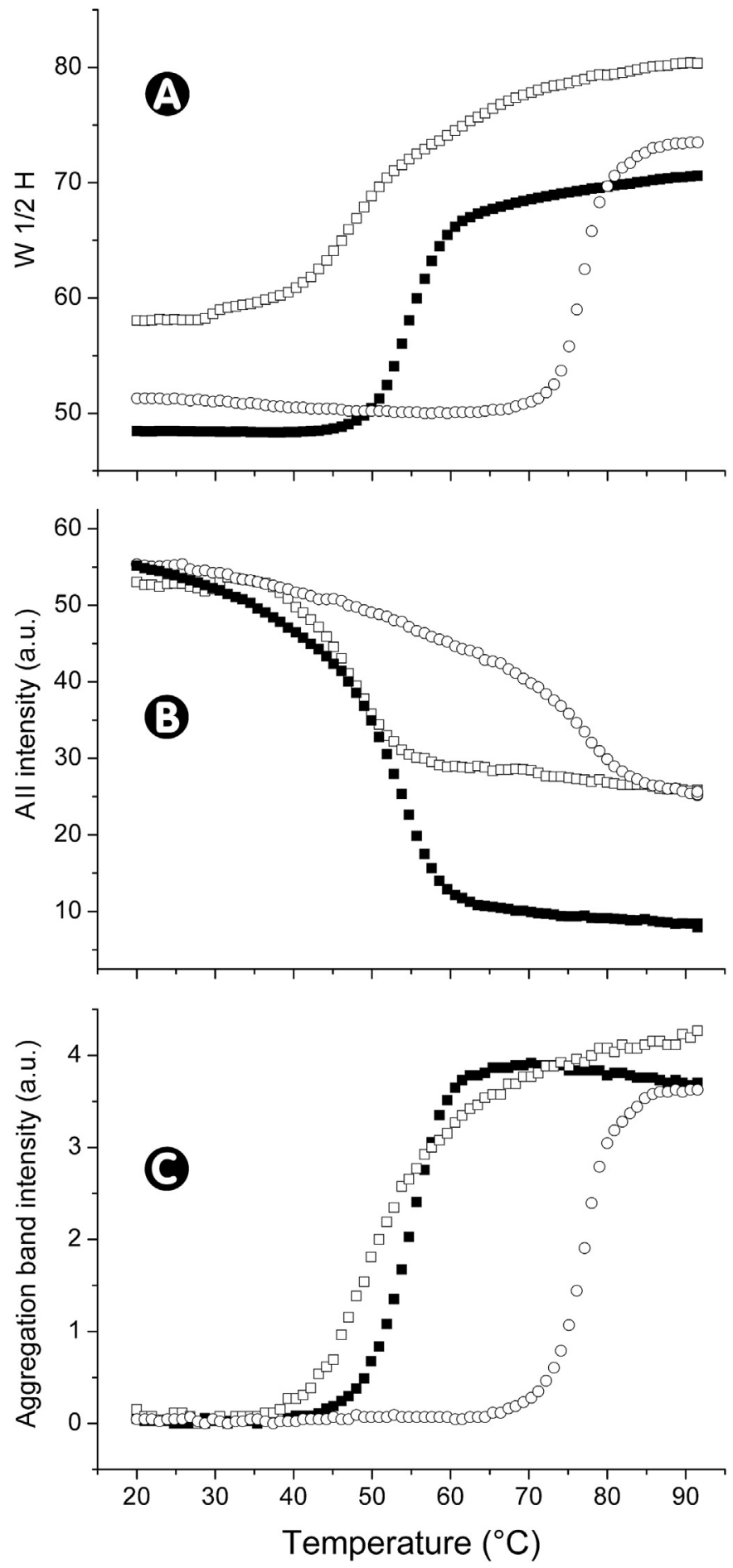

Fig. 5. - Temperature-dependent changes in IR spectral parameters for $\gamma$-conglutin at $\mathrm{p}^{2} \mathrm{H} 4.5$ in the absence and in the presence of DMPG or DOPA. Absence of PLs (symbol $\square$ ); presence of DMPG (symbol $\square$ ); presence of DOPA (symbol O). Panel A: plots of the width of the amide I' band calculated at one-half of the amide $\mathrm{I}^{\prime}$ band height $(\mathrm{W} 1 / 2 \mathrm{H})$ as a function of temperature. Panel B: plots of the intensity of the residual amide II band (AII intensity) as a function of temperature. Panel C: plots of the intensity of the band related to protein aggregation $\left(1615 \mathrm{~cm}^{-1}\right)$ as a function of temperature. Melting temperatures $\left(T_{\mathrm{m}}\right)$ and half deuteration temperatures $\left(\mathrm{T}_{\mathrm{D} 1 / 2}\right)$ are reported in Table 2. Onset of aggregation correspond to $49{ }^{\circ} \mathrm{C}$ in the absence of PLs, $43^{\circ} \mathrm{C}$ in the presence of DMPG and $72{ }^{\circ} \mathrm{C}$ in the presence of DOPA. 
The results of the fitting procedure for $\mathrm{W} 1 / 2 \mathrm{H}$ or AII intensity of $\gamma$ conglutin at $\mathrm{p}^{2} \mathrm{H} 4.5$ in the absence and in the presence of DMPG or DOPA by applying (1) are reported in Table 2 . The analysis indicates that either DMPG or DOPA influence the thermal stability of $\gamma$-conglutin at $\mathrm{p}^{2} \mathrm{H} 4.5$ but in opposite ways. DOPA increases remarkably the thermal restrain of $\gamma$-conglutin, shifting the $T_{\mathrm{m}}$ at $\mathrm{p}^{2} \mathrm{H} 4.5$ from $54.6^{\circ} \mathrm{C}$ to $76.9^{\circ} \mathrm{C}$ while DMPG has a light destabilizing effect on the thermal restrain of $\gamma$-conglutin, shifting the $T_{\mathrm{m}}$ at $\mathrm{p}^{2} \mathrm{H} 4.5$ from $54.6^{\circ} \mathrm{C}$ to $50.8^{\circ} \mathrm{C}$. In addition, even the onset of aggregation in the presence of DOPA is shifted to $72{ }^{\circ} \mathrm{C}$ (Fig. 5C) showing that the presence of DOPA increases the strength of $\gamma$-conglutin to thermal denaturation/aggregation. The values of $T_{\mathrm{m}}$ and onset of aggregation at $\mathrm{p}^{2} \mathrm{H} 4.5$ in the presence of DOPA are very similar to the ones obtained for $\gamma$-conglutin at $\mathrm{p}^{2} \mathrm{H}$ 7.0. It is reasonable to argue that the interaction with DOPA promotes the oligomerization of $\gamma$-conglutin even at $\mathrm{p}^{2} \mathrm{H} 4.5$.

Preliminary experiments on the binding of $\gamma$-conglutin to SUVs of the anionic PLs DMPG or DOPA produced the instantaneous formation of aggregates, even if SUVs and $\gamma$-conglutin solutions were prepared in the presence of $0.1 \mathrm{M} \mathrm{NaCl}$. Therefore, to moderate this effect, binding of $\gamma$-conglutin to DMPG and DOPA was assessed by monitoring the turbidity of SUVs made of DMPC:DMPG (50:50) and DOPC:DOPA (50:50) mixtures in the presence of increasing concentrations of $\gamma$ conglutin. In addition, a control with SUVs made of neutral PLs (DMPC and DOPC) was performed, in order to check that the increasing of turbidity of the mixtures was effectively due to the binding of $\gamma$-conglutin to anionic PLs. A fixed amount $(150 \mu \mathrm{M})$ of the PLs prepared as SUVs was titrated with various concentrations of $\gamma$-conglutin: $0-16 \mu \mathrm{M}$ for DMPC or DMPC:DMPG mixture and $0-3 \mu \mathrm{M}$ for DOPC or DOPC:DOPA mixture. Fig. 6 displays the results of binding experiments, where it stands out a great increase in turbidity of the DOPC:DOPA mixture, as compared to the control DOPC (Fig. 6A). Indeed, in the presence of $3.0 \mu \mathrm{M}$ of $\gamma$-conglutin, the turbidity of DOPC:DOPA mixture is almost ten-fold increased respect to DOPC only. The binding, even if less pronounced compared to DOPC:DOPA mixture, has been observed also for DMPC:DMPG mixture (Fig. 6B). It is worth noting that, in order to obtain useful turbidity data to fit, for the DMPC:DMPG sample it was necessary to increase five-fold $(0-16.0 \mu \mathrm{M})$ the $\gamma$-conglutin concentration range. A little increase in turbidity has been observed also for the control samples made of neutral DOPC or DMPC, suggesting that the binding of $\gamma$-conglutin to SUVs made of DOPC:DOPA or DMPC:DMPG mixtures is mainly due to ionic interactions with acidic PLs, but a little contribution may derive also from hydrophobic interactions. Anyhow, the data suggest that the positively charged surface of $\gamma$-conglutin is involved in the interaction with anionic SUVs, and this is especially evident for the interaction with DOPC:DOPA (Fig. 6A).

Finally, we determined the binding affinity between $\gamma$-conglutin and SUVs made of DOPC:DOPA (50:50) or DMPC:DMPG (50:50) mixtures. The turbidity data were fitted as described in Materials and Methods, yielding an apparent dissociation constant $(\mathrm{Kd})$ of $0.17 \pm 0.01 \mu \mathrm{M}$ for DOPC:DOPA or $2.53 \pm 0.36 \mu \mathrm{M}$ for DMPC:DMPG (Fig. 6), indicating high-affinity binding of $\gamma$-conglutin to anionic SUVs with DOPA.

In conclusion, the most peculiar novelty of the present work consists in the assessment of the effects of DMPG or DOPA on the thermal stability of $\gamma$-conglutin. DMPG has little destabilizing effect while DOPA exerts a great stabilizing effect, increasing the $T_{\mathrm{m}}$ of $\gamma$-conglutin at $\mathrm{p}^{2} \mathrm{H}$ 4.5 of more than $20^{\circ} \mathrm{C}$ (from $54.6^{\circ} \mathrm{C}$ to $76.9^{\circ} \mathrm{C}$ ). This $T_{\mathrm{m}}$ is comparable to the one $\left(74.9^{\circ} \mathrm{C}\right)$ calculated at $\mathrm{p}^{2} \mathrm{H} 7.0$ for the protein alone, therefore it is quite probable that the increased $T_{\mathrm{m}}$ at $\mathrm{p}^{2} \mathrm{H} 4.5$ is due to the presence of the multimeric form of the protein. Since $\gamma$-conglutin at $\mathrm{p}^{2} \mathrm{H}$ 4.5 is in the monomeric status, the interaction with DOPA likely promotes the oligomerization even at $\mathrm{p}^{2} \mathrm{H}$ 4.5. Turbidity data showed highaffinity binding of $\gamma$-conglutin to anionic SUVs made of DOPA.

The molecular features outlined of this study are relevant to address the applicative exploitation and to delineate a deeper comprehension of the natural biological role of $\gamma$-conglutin. Because of their stabilizing and protective effects, SUVs may be useful carriers for nutraceutical
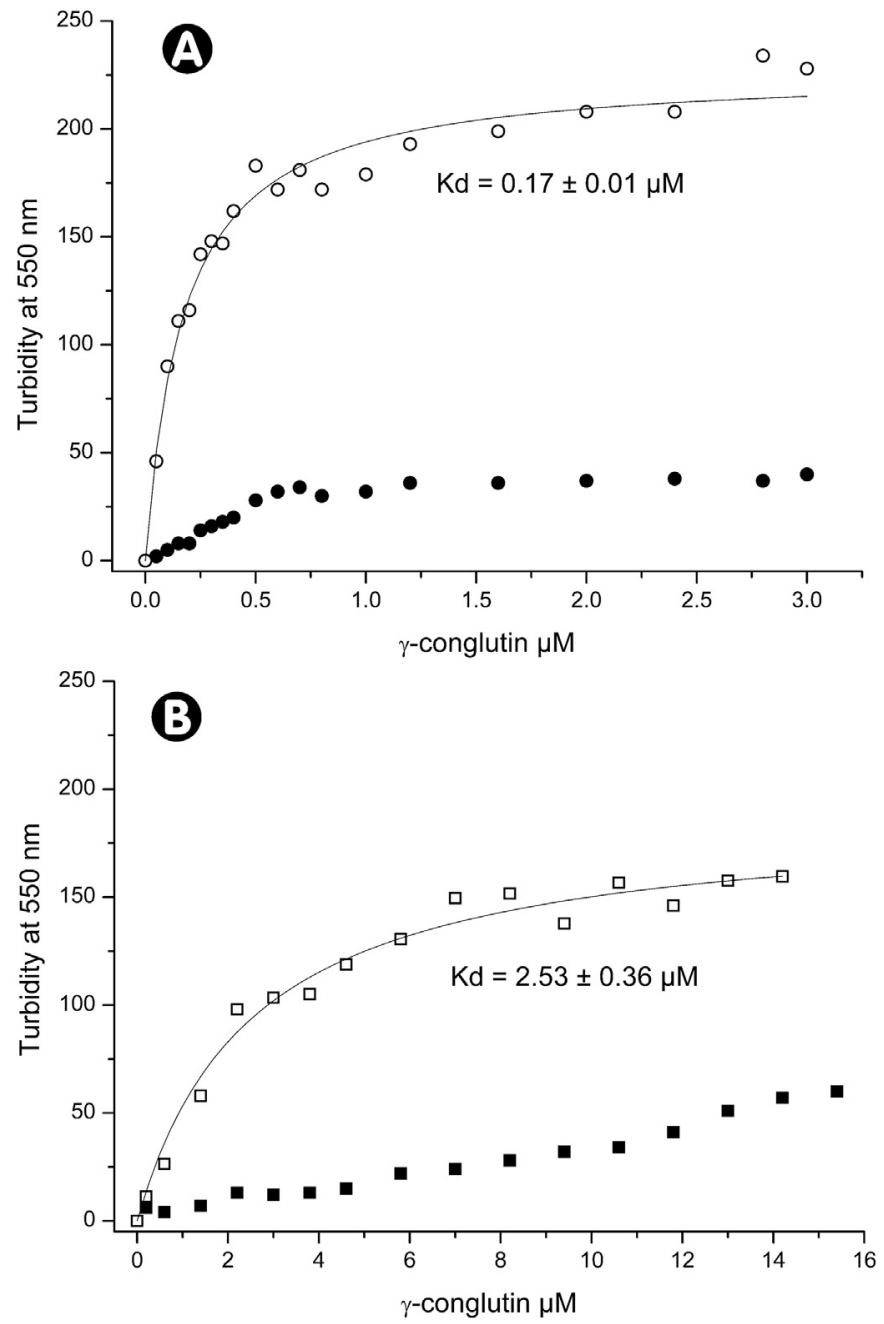

Fig. 6. - Binding of $\gamma$-conglutin to anionic DOPC:DOPA or DMPC:DMPG SUVs, monitored by increasing of turbidity. Turbidity was measured spectrophotometrically at $550 \mathrm{~nm}$, the concentration of PLs in all samples was $150 \mu \mathrm{M}$. Measurements were done at $25^{\circ} \mathrm{C}$ for DOPC ( $\bullet$ ) and DOPC:DOPA (O) (50:50) mixture (panel A) and at $35^{\circ} \mathrm{C}$ for DMPC ( $\square$ ) and DMPC:DMPG ( $\square$ ) (50:50) mixture (panel B), DOPC and DMPC SUVs samples were done as controls. Data were fitted to a one-site binding hyperbolic curve (solid line), yielding a Kd of $0.17 \pm 0.01 \mu \mathrm{M}$ for DOPC:DOPA and $2.53 \pm 0.36 \mu \mathrm{M}$ for DMPC:DMPG.

applications or for studies aimed to investigate the metabolic fate of orally administered $\gamma$-conglutin and the cellular mechanisms at the basis of its observed effects. Regarding its natural physiological role, $\gamma$ conglutin was localized in the apoplasts of germinating seeds while the storage vacuoles appeared void of the protein [29]. How $\gamma$-conglutin reaches the extracellular regions is still matter of debate. The hypothesis that the seed-stored protein is released outside the cells through an unconventional secretory vesicles-based pathway, as it occurs for sunflower seed agglutinin 1 [30] and other seed proteins [31-33], is suggestive and needs focused investigations. If instead $\gamma$-conglutin is $d e$ novo synthesized and secreted into the apoplasts during germination to prevent the effects of biotic and abiotic stresses, our results support the inhibitory function of $\gamma$-conglutin against cell wall-acting endo-glucanases released by pathogens [1] and shed light on the molecular mechanisms at the basis of its action. The $\mathrm{pH}$ of apoplast, naturally acidic, increases during pathogen attacks and in response to drought or salinity [34], ensuring a more favourable condition to preserve the native status $\gamma$-conglutin outside the cell, since the protein becomes susceptible to proteolysis at $\mathrm{pH}$ values below $4.5[35,36]$. 


\section{Acknowledgements}

This work was supported by a Grant from Università Politecnica delle Marche, Ancona (Italy). JC was supported by Università degli Studi di Milano.

\section{References}

[1] A. Scarafoni, A. Ronchi, M. Duranti, Gamma-Conglutin, the Lupinus albus XEGIPlike protein, whose expression is elicited by chitosan, lacks of the typical inhibitory activity against GH12 endo-glucanases, Phytochemistry 71 (2010) 142-148.

[2] Q. Qin, C.W. Bergmann, J.K. Rose, M. Saladie, V.S. Kolli, P. Albersheim, A.G. Darvill, W.S. York, Characterization of a tomato protein that inhibits a xyloglucan-specific endoglucanase, Plant J. 34 (2003) 327-338.

[3] A. Scarafoni, A. Consonni, S. Pessina, S. Balzaretti, J. Capraro, E. Galanti, M. Duranti, Structural basis of the lack of endo-glucanase inhibitory activity of Lupinus albus gamma-conglutin, Plant Physiol. Biochem. 99 (2016) 79-85.

[4] J.C. Bertoglio, M.A. Calvo, J.L. Hancke, R.A. Burgos, A. Riva, P. Morazzoni, C. Ponzone, C. Magni, M. Duranti, Hypoglycemic effect of lupin seed gamma-conglutin in experimental animals and healthy human subjects, Fitoterapia 82 (2011) 933-938.

[5] C. Magni, F. Sessa, E. Accardo, M. Vanoni, P. Morazzoni, A. Scarafoni, M. Duranti, Conglutin gamma, a lupin seed protein, binds insulin in vitro and reduces plasma glucose levels of hyperglycemic rats, J. Nutr. Biochem. 15 (2004) 646-650.

[6] I.M. Lacroix, E.C. Li-Chan, Overview of food products and dietary constituents with antidiabetic properties and their putative mechanisms of action: a natural approach to complement pharmacotherapy in the management of diabetes, Mol. Nutr. Food Res. 58 (2014) 61-78.

[7] J. Capraro, A. Clemente, L.A. Rubio, C. Magni, A. Scarafoni, M. Duranti, Assessment of the lupin seed glucose-lowering protein intestinal absorption by using in vitro and ex vivo models, Food Chem. 125 (2011) 1279-1283.

[8] J. Capraro, C. Magni, F. Faoro, D. Maffi, A. Scarafoni, G. Tedeschi, E. Maffioli, A. Parolari, C. Manzoni, M.R. Lovati, M. Duranti, Internalisation and multiple phosphorylation of gamma-Conglutin, the lupin seed glycaemia-lowering protein, in HepG2 cells, Biochem. Biophys. Res. Commun. 437 (2013) 648-652.

[9] A. Scire, M. Baldassarre, R. Galeazzi, F. Tanfani, Fibrillation properties of human alpha(1)-acid glycoprotein, Biochimie 95 (2013) 158-166.

[10] A. Scire, M. Baldassarre, G. Lupidi, F. Tanfani, Importance of $\mathrm{pH}$ and disulfide bridges on the structural and binding properties of human alpha(1)-acid glycoprotein, Biochimie 93 (2011) 1529-1536.

[11] V. Borromeo, J. Sereikaite, V.A. Bumelis, C. Secchi, A. Scire, A. Ausili, F. Tanfani Auria, Mink growth hormone structural-functional relationships: effects of renaturing and storage conditions, Protein J. 27 (2008) 170-180.

[12] M. Sanchez, A. Scire, F. Tanfani, A. Ausili, The thermal unfolding of the ribosomeinactivating protein saporin-S6 characterized by infrared spectroscopy, Biochim. Biophys. Acta 1854 (2015) 1357-1364.

[13] M. Baldassarre, R. Galeazzi, B. Maggiore, F. Tanfani, A. Scire, Bovine alpha(1)-acid glycoprotein, a thermostable version of its human counterpart: insights from Fourier transform infrared spectroscopy and in silico modelling, Biochimie 102 (2014) 19-28.

[14] T. Koper, A. Polit, A. Sobiecka-Szkatula, K. Wegrzyn, A. Scire, D. Figaj, L. Kadzinski, U. Zarzecka, D. Zurawa-Janicka, B. Banecki, A. Lesner, F. Tanfani, B. Lipinska, J. Skorko-Glonek, Analysis of the link between the redox state and enzymatic activity of the HtrA (DegP) protein from Escherichia coli, PLoS One 10 (2015) e0117413.

[15] A. Sobiecka-Szkatula, A. Polit, A. Scire, A. Gieldon, F. Tanfani, Z. Szkarlat, J. Ciarkowski, D. Zurawa-Janicka, J. Skorko-Glonek, B. Lipinska, Temperature-induced conformational changes within the regulatory loops L1-L2-LA of the HtrA heat-shock protease from Escherichia coli, Biochim. Biophys. Acta 1794 (2009)
1573-1582.

[16] M.T. Caccamo, S. Magazù, Thermal restraint on PEG-EG mixtures by FTIR investigations and wavelet cross-correlation analysis, Polym. Test. 62 (2017) 311-318

[17] S. Magazù, F. Migliardo, M.T. Caccamo, Upgrading of resolution elastic neutron scattering (RENS), Adv. Mater. Sci. Eng. 2013 (2013) 1-7.

[18] R. Tunuguntla, M. Bangar, K. Kim, P. Stroeve, C.M. Ajo-Franklin, A. Noy, Lipid bilayer composition can influence the orientation of proteorhodopsin in artificia membranes, Biophys. J. 105 (2013) 1388-1396.

[19] P. Goloubinoff, A. Mogk, A.P. Zvi, T. Tomoyasu, B. Bukau, Sequential mechanism of solubilization and refolding of stable protein aggregates by a bichaperone network, Proc. Natl. Acad. Sci. U. S. A. 96 (1999) 13732-13737.

[20] J. Capraro, P. Spotti, C. Magni, A. Scarafoni, M. Duranti, Spectroscopic studies on the $\mathrm{pH}$-dependent structural dynamics of gamma-conglutin, the blood glucoselowering protein of lupin seeds, Int. J. Biol. Macromol. 47 (2010) 502-507.

[21] J. Czubinski, J. Barciszewski, M. Gilski, K. Szpotkowski, J. Debski, E. LampartSzczapa, M. Jaskolski, Structure of gamma-conglutin: insight into the quaternary structure of 7S basic globulins from legumes, Acta Crystallogr. D Biol. Crystallogr. 71 (2015) 224-238.

[22] T. Yoshizawa, T. Shimizu, M. Yamabe, M. Taichi, Y. Nishiuchi, N. Shichijo, S. Unzai, H. Hirano, M. Sato, H. Hashimoto, Crystal structure of basic 7S globulin, a xyloglucan-specific endo-beta-1,4-glucanase inhibitor protein-like protein from soybean lacking inhibitory activity against endo-beta-glucanase, FEBS J. 278 (2011) 1944-1954.

[23] A. Barth, Infrared spectroscopy of proteins, Biochim. Biophys. Acta 1767 (2007) 1073-1101.

[24] S. Krimm, J. Bandekar, Vibrational spectroscopy and conformation of peptides, polypeptides, and proteins, Adv. Protein Chem. 38 (1986) 181-364.

[25] A. Marabotti, A. Ausili, M. Staiano, A. Scire, F. Tanfani, A. Parracino, A. Varriale, M. Rossi, S. D'Auria, Pressure affects the structure and the dynamics of the D-galactose/D-glucose-binding protein from Escherichia coli by perturbing the C-terminal domain of the protein, Biochemistry 45 (2006) 11885-11894.

[26] A. Barth, The infrared absorption of amino acid side chains, Prog. Biophys. Mol. Biol. 74 (2000) 141-173.

[27] M. Duranti, F. Sessa, A. Scarafoni, T. Bellini, F. Dallocchio, Thermal stabilities of lupin seed conglutin gamma protomers and tetramers, J. Agric. Food Chem. 48 (2000) 1118-1123.

[28] A.A. Hamama, H.L. Bhardwaj, Phytosterols, triterpene alcohols, and phospholipids in seed oil from White Lupin, JAOCS 81 (2004) 1039-1044.

[29] M. Duranti, A. Scarafoni, C. Gius, A. Negri, F. Faoro, Heat-induced synthesis and tunicamycin-sensitive secretion of the putative storage glycoprotein conglutin gamma from mature lupin seeds, Eur. J. Biochem. 222 (1994) 387-393.

[30] M. Regente, G. Corti-Monzon, A.M. Maldonado, M. Pinedo, J. Jorrin, L. de la Canal, Vesicular fractions of sunflower apoplastic fluids are associated with potential exosome marker proteins, FEBS Lett. 583 (2009) 3363-3366.

[31] Y. Ding, J. Wang, J. Wang, Y.D. Stierhof, D.G. Robinson, L. Jiang, Unconventional protein secretion, Trends Plant Sci. 17 (2012) 606-615.

[32] N. Hatsugai, S. Iwasaki, K. Tamura, M. Kondo, K. Fuji, K. Ogasawara, M. Nishimura, I. Hara-Nishimura, A novel membrane fusion-mediated plant immunity against bacterial pathogens, Genes Dev. 23 (2009) 2496-2506.

[33] C. Krause, S. Richter, C. Knoll, G. Jurgens, Plant secretome - from cellular process to biological activity, Biochim. Biophys. Acta 1834 (2013) 2429-2441.

[34] C.M. Geilfus, The $\mathrm{pH}$ of the Apoplast: Dynamic factor with functional impact under stress, Mol. Plant 10 (2017) 1371-1386.

[35] J. Capraro, C. Magni, A. Scarafoni, M. Duranti, Susceptibility of lupin gammaconglutin, the plasma glucose-lowering protein of lupin seeds, to proteolytic enzymes, J. Agric. Food Chem. 57 (2009) 8612-8616.

[36] M. Duranti, C. Gius, F. Sessa, G. Vecchio, The saccharide chain of lupin seed conglutin gamma is not responsible for the protection of the native protein from degradation by trypsin, but facilitates the refolding of the acid-treated protein to the resistant conformation, Eur. J. Biochem. 230 (1995) 886-891. 